\title{
Labor costs management in the large-block construction of NPP
}

\author{
Andrey Morozenko*, and Alexey Shashkov \\ Moscow State University of Civil Engineering, Yaroslavskoe shosse, 26, Moscow, 129337, Russia
}

\begin{abstract}
The article continues the research of the features of the use of prefabricated cast-in-place structures in the construction of nuclear power plants (NPP), the organizational and economic feasibility of the use of prefabricated cast-in-place structures in the implementation of new projects for the construction of nuclear power plants. The estimation of labor costs and resource costs of installation of large-block structures for the reactor building of the NPP was made. The dependence of labor costs for the installation of reinforced blocks, depending on the share of using reinforced blocks during the construction of the reactor building of a nuclear power plant, was obtained. The dependence of the overall labor costs for the industrial production and installation of reinforced blocks, depending on the share of using reinforced blocks during the construction of the reactor building of a nuclear power plant, was obtained. Graphical representations of dependencies are illustrated. The main daily resource consumption for the installation of reinforced blocks during large-block construction has been analytically calculated. The data on the required shares of labor costs at industrial enterprises and at the construction site in percentage terms were obtained. The conclusion is made about the rational use of large-block construction in the implementation of NPP construction projects.
\end{abstract}

\section{Introduction}

The need to create competitive projects requires a reduction in the estimated cost of building nuclear power plants (NPPs). This is especially true when concluding international agreements for the construction of stations. One of the ways to reduce the cost of implementing an investment and construction project for the construction of a nuclear power plant is to reduce the duration of construction. Reduced construction time provides economic benefits due to early commissioning of power units. Consequently, the payback period of the project is shortened: the station starts generating and selling electricity earlier. It was shown that the introduction of 1 power unit with an electric capacity of $1200 \mathrm{MW} 1$ year earlier allows achieving an early return on investment in the amount of \$ 145-790 million per year, depending on the region of construction of the station (at the rate of the Central Bank of the Russian Federation for February 2021) [1].

The target dates for the construction of the most modern Russian project of NPP VVER-TOI are the commissioning of the first unit 48 months after the start of construction,

\footnotetext{
${ }^{*}$ Corresponding author: morozenkoaa@mgsu.ru
} 
the subsequent ones - 40) [2]. At present, the actual construction time for one power unit is 60 months or more. One of the ways to achieve such a high rate of construction should be a high degree of use of industrial structures. [3]. Among such structures, the most promising are prefabricated cast-in-place structures. They represent a reinforcement block with a permanent formwork made of metal sheets or steel fiber concrete panels $[4,5]$.

The most labor-intensive construction among the complex of buildings and structures of a nuclear power plant has a reactor building. That it is lies on the critical path of the calendar schedule and largely determines the total construction time of the NPP power unit. The main building structures in the reactor building are reinforced concrete structures. At present, most of the ongoing nuclear power plant construction projects use the traditional technology of erection of cast-in-place structures in the manufacture of reinforced concrete structures. In it, reinforcement of reinforced concrete structures is performed with separate reinforcing bars. This technology does not allow achieving a high construction speed, since all work takes place in a limited area. The so-called "lack of space" factor arises. Because of this, it is often impossible to organize a high flow rate of work. The work has to be performed sequentially, some technological breaks occur. This does not allow to linearly increasing the productivity of work by linearly increasing the number of labor force [6].

The use of reinforced formwork blocks allows one to shift part of the labor costs from the construction site, which has physical size limitations, to the construction and installation base, the area of which may exceed the area of the construction site. In addition, the area of the construction and installation base, if necessary, can be increased while increasing the pace and volume of construction [7]. It is also possible to increase the capacity of the industrial production of blocks by using existing plant production, both near the construction site and at a great distance, if there is a possibility of delivering large blocks to the construction site of the NPP [8]. The main work that takes place directly at the construction site is the installation of reinforced formwork blocks and related work to prepare them for concreting.

To organize an effective process for the construction of buildings and structures of the NPP complex, it is necessary to competently organize the design of the units, the industrial production of the units, their delivery to the construction site and the subsequent assembly of the units. This is possible in the event of a structural reorganization of the investment and construction project for the construction of a nuclear power plant due to the competent redistribution of labor costs between the participants in the construction project. When forming an investment and construction project, it is important to determine the required degree of use of industrial structures to achieve the specified deadlines for the delivery of objects. However, it is also important to take into account a number of restrictions associated with the degree of development of material and production bases at the construction site. This is especially true when implementing foreign projects for the construction of nuclear power plants [9].

A hypothesis is put forward according to which, due to the transfer of part of the labor costs from the construction site (during the transition from reinforcement with separate rods to the production of reinforced formwork blocks) to the factory facilities, it is possible to reduce the total duration of the construction of the building by reducing the time of construction and installation work. To test this hypothesis, it is necessary to determine the labor costs and the required resources at least for factory production and installation of reinforced blocks. This article provides a detailed method for determining the labor and resource costs of assembling prefabricated reinforced formwork blocks and a set of related works. The method for determining the labor and resource costs of the industrial production of reinforced formwork blocks in the factory workshops was researched earlier [9]. 


\section{Methods}

The main research method is the resource method [10]. Based on the assessment of the required resources, the dependence of the amount of labor costs for industrial production, the installation of reinforced blocks and additional work on preparation for concreting, is determined, depending on the share of using reinforced blocks during the construction of the reactor building of the NPP. Resources are estimated based on a sample of statistical data from real production, which provides the closest to real values.

Labor and resource costs for the installation of reinforced formwork structures were determined based on statistical data on the installation of units of the third tier of the inner containment (IC) of the AES-2006 design power unit under construction. Data was collected on the installation of 12 reinforced formwork blocks on the territory of the NPP construction site, which are a closed tier with various types of blocks. Blocks of other tiers of inner containment are fundamentally similar to each other. The initial data were the geometric dimensions of the blocks based on the working documentation, data on the equipment used during installation and related work, data on the number and composition of the team of workers, as well as the daily work schedule. All collected data was analyzed and presented in the correct format. As the results of the calculation, it is necessary to obtain the required labor costs for the installation of different types of blocks, the dependence in human labor costs depending on the percentage of the total volume of structures erected by the industrial method, as well as the necessary resources for the installation of these structures.

Labor costs for concreting structures are not taken into account, since for any type of reinforcement work (traditional and block), concreting occurs in the same way. The labor costs for concreting in both cases can be considered conditionally the same. In addition, preparatory work (garbage collection, preparation of the concrete working joint) is not taken into account, since they are also similar in both cases.

Extrapolation of data on labor costs and resource costs for the installation of inner containment blocks on blocks for the construction of other reinforced concrete structures of the reactor building is carried out by excluding production processes that are characteristic only of inner containment blocks. It is assumed that when extrapolating data on the labor intensity of the manufacture of blocks into blocks of different thicknesses, it is assumed that the labor intensity of processes, the volume of which depends on the area of the front surface of the block, does not depend on the thickness. And the complexity of processes, the volume of which depends on the thickness of the block, depends on it in direct proportion.

When constructing the dependence of the amount of labor costs for the installation of reinforced blocks, depending on the share of using reinforced blocks during the construction of the reactor building of a nuclear power plant, the result is determined depending on the choice of specific structures for manufacturing in prefabricated cast-inplace structures. Thus, the dependence is graphically depicted by the range of possible values, limited by the maximum and minimum possible values.

\section{Results}

The dimensions of the blocks were determined by the following parameters: height $14 \mathrm{~m}$, sector angle $27-36^{\circ}$, inner radius $22 \mathrm{~m}$, wall thickness $1.2 \mathrm{~m}$, length on the outside 10.9-14.6 m. On average, the blocks under consideration limit the volume of cast-in-place reinforced concrete in size $198.8 \mathrm{~m}^{3} .12$ such units are used in one inner containment tier. To carry out installation work at the construction site, the following equipment is used: a crawler crane with a lifting capacity of $1350 \mathrm{t}-1$ unit, tower cranes - 4 units, an onboard 
vehicle - 6 units, a trailer - 1 unit. The number of workers in the main team is 28 people per shift. The work is carried out in 2 shifts of 10 working hours.

The total installation time for one IC tier is from 75 to 100 days. This range of values occurs when using different types of blocks. In the AES-2006 design, these blocks have a permanent formwork on only one side. Therefore, it takes 19 days to install the inventory formwork from the second side, as well as 6 days to remove the formwork. In our study, we will make the assumption that all the blocks we are considering have a permanent formwork on both sides. The impossibility of using fixed formwork in all reinforced concrete structures of the reactor building will be taken into account by using the maximum percentage of the required share of building manufacturing in industrial structures.

Let's assume the duration of installation of 1 tier of inner containment blocks is equal to 75 days. Of these, 36 days are the assembly of blocks with a crane and setting in the design position, unfastening and racking the block. Let's designate them as "assembly processes". 39 days are required for the following set of works: installation of docking reinforcing bars, installation of transverse reinforcement at joints, installation of docking plates, sealing of joints. Let's call them "butt processes". We get that the average labor costs for the installation of 1 block of the inner containment are 3500 man-hours. The calculation was made according to the formula:

$\overline{C_{I C}}=\frac{n_{\text {worker }} \cdot t_{\text {shift }} \cdot n_{\text {shift }} \cdot t_{\text {total }}}{n_{\text {block }}}=\frac{28 \mathrm{man} \cdot 10 \mathrm{~h} \cdot 2 \text { day }^{-1} \cdot 75 \text { day }}{12}=3500 \mathrm{man}-\mathrm{h}$

$\overline{C_{I C}}$ - average labor costs for the installation of 1 unit of the IC, man-h;

$n_{\text {worker }}$ - the number of workers in a brigade in 1 shift, people;

$t_{\text {shift }}$ - shift duration (working time), h;

$n_{\text {shift }}$ - the number of shifts per day, day ${ }^{-1}$;

$n_{\text {block }}-$ the number of blocks in 1 IC tier;

$t_{\text {total }}-$ total duration of production of 1 IC tier.

Thus, for the walls of the inner containment shell, the specific averaged labor costs for assembling blocks, expressed per $1 \mathrm{~m}^{3}$ of concrete of structures limited by the block, will be:

$\overline{C_{I C}}=\frac{\overline{C_{I C}}}{\overline{V_{I C}}}=\frac{3500 \mathrm{man}-h}{198.8 \mathrm{~m}^{3}}=17.6(\mathrm{man}-h) / \mathrm{m}$

$\overline{\overline{C_{I C}}}$ - specific averaged labor costs for the installation of IC units, (man-h) $/ \mathrm{m}^{3}$;

$\overline{C_{I C}}$ - the average labor costs for the production of 1 unit of the IC, man-h;

$\frac{V_{I C}}{I C}-$ volume of concrete of structures, limited by the block, $\mathrm{m}^{3}$.

We extrapolate the values obtained for the inner containment block to other structures of the reactor building. Fixed formwork and working reinforcement are located on two planes of the blocks. Therefore, the complexity of butt processes depends only on the surface area of the block and does not depend on its thickness. It turns out that when calculating the specific labor intensity (for $1 \mathrm{~m}^{3}$ of concrete of structures limited by a block, it will be), the values will change in inverse proportion to the thickness. For example, if a block with an equal area has 2 times less thickness than a IC block, the complexity of making butt joints does not change. However, the volume of concrete of structures, limited by the block, will decrease by 2 times. Accordingly, the specific labor intensity will increase 2 times.

As a rule, reinforced formwork blocks are produced with the same assembly mass. This makes it possible to unify the equipment used. Thus, with an equal mass, the volume of concrete of the structures bounded by the block will be equal. Consequently, both the total and specific labor intensity of the installation processes will not change. Based on the fractions of the duration of these two groups of processes, we obtain a formula for determining the average specific labor costs of blocks of any thickness:

$$
\overline{c_{\delta}}=\overline{c_{I C}} \cdot\left(\frac{39 \text { day }}{75 \text { day }} \cdot \frac{1.2 m}{\delta_{i}}+\frac{36 \text { day }}{75 \text { day }}\right)=\overline{C_{I C}} \cdot\left(\frac{0.624 m}{\delta_{i}}+0.48\right)
$$


$\overline{c_{\delta}}-$ specific averaged labor costs for the production of blocks with thickness $\delta_{i}$, (man-h) $/ \mathrm{m}^{3}$;

$\overline{C_{I C}}-$ specific averaged labor costs for the production of IC blocks with a thickness of $1.2 \mathrm{~m},\left(\right.$ man-h) $/ \mathrm{m}^{3}$;

$\delta_{i}$ - block thickness, $\mathrm{m}$

To determine labor costs for various degrees of use of reinforced formwork blocks during the construction of a nuclear power plant reactor building, we will focus on the volumes of cast-in-place concrete in the building structures obtained based on statistical data. Statistical data were obtained from the analysis of the design documentation of the reactor building of the AES-2006 design. The distribution of the volumes of cast-in-place concrete over the structures of the reactor building is given in Table 1.

Table 1. Distribution of cast-in-place concrete volumes by reactor building structures

\begin{tabular}{|l|c|c|c|}
\hline \multicolumn{1}{|c|}{ Design name } & $\begin{array}{c}\text { Concrete } \\
\text { volume, } \mathrm{m}^{3}\end{array}$ & $\begin{array}{c}\text { The average } \\
\text { thickness of the } \\
\text { structure, } \mathrm{m}\end{array}$ & $\begin{array}{c}\text { Share in the total } \\
\text { concrete volume } \\
\text { of the building, } \%\end{array}$ \\
\hline Foundation slab & 17062 & 3.0 & 17.9 \\
\hline Transport portal & 1056 & 1.5 & 1.1 \\
\hline Contour walls & 6289 & 0.5 & 6.6 \\
\hline Annex & 29420 & 0.4 & 30.9 \\
\hline Accident confinement area (ACA) & 16618 & 1.0 & 17.4 \\
\hline Outer containment (OC) & 6317 & 0.5 & 6.6 \\
\hline Inner containment (IC) & 13462 & 1.2 & 14.1 \\
\hline Passive heat removal system (PHRS) & 5106 & 0.5 & 5.4 \\
\hline
\end{tabular}

When deciding on the degree of use of industrially manufactured blocks in the construction of a nuclear power plant, the IC is the priority design. In this case, this structure is erected with the help of reinforced blocks entirely. Therefore, the dependence of the increase in labor costs for the manufacture of reinforced blocks will first increase in an abrupt manner by the amount of labor costs for the manufacture of IC blocks.

Average specific labor costs for the production of conventional blocks of various thicknesses, calculated according to the above formula to determine the average specific labor costs of blocks of any thickness (3) based on the data from Table 1 are given in Table 2.

Table 2. Averaged specific labor costs for the production of conventional blocks of various thicknesses

\begin{tabular}{|c|c|}
\hline $\begin{array}{c}\text { The average thickness } \\
\text { of the structure, } \mathrm{m}\end{array}$ & $\begin{array}{c}\text { Specific labor costs, } \\
(\mathrm{man}-\mathrm{h}) / \mathrm{m}^{3}\end{array}$ \\
\hline 0.4 & 35.9 \\
\hline 0.5 & 30.4 \\
\hline 1.0 & 19.4 \\
\hline 1.2 & 17.6 \\
\hline 1.5 & 15.8 \\
\hline 3.0 & 12.1 \\
\hline
\end{tabular}

Based on the data obtained, we derive the dependence, taking as $1 \%$ of the use of reinforced blocks in the total volume of reinforced concrete structures of the reactor building, $953.3 \mathrm{~m}^{3}$. The analytical form of the median of this dependence will look as follows:

$$
\mathrm{C}_{\text {inst }}=24925.665 \cdot x-114520.7
$$

$\mathrm{C}_{\text {inst }}$ - labor intensity of the installation of reinforced blocks for the reactor building of the NPP, man-h; 
$x$ - the required share of manufacturing reinforced concrete structures of a reactor building in industrial structures, $\%$.

It should be borne in mind that the minimum share of $\mathrm{x}$ can be equal to $14.1 \%$ (production of IC in industrial structures). At values less than $14.1 \%$, labor intensity will be zero.

This dependence is shown in the form of a space bounded by broken lines showing the boundary indicators of the increase in labor costs, shown in Figure 1. The presence of space, and not a single graph, is due to variations in the sequence of erection of blocks of different thicknesses. It should be borne in mind that labor costs with a share of using reinforced blocks of over $80 \%$ are purely theoretical, since the real share of using industrial structures rarely exceeds $80 \%$ of the total volume of buildings. The remaining $20 \%$ or more are structures of complex shapes, erected in inventory formwork.

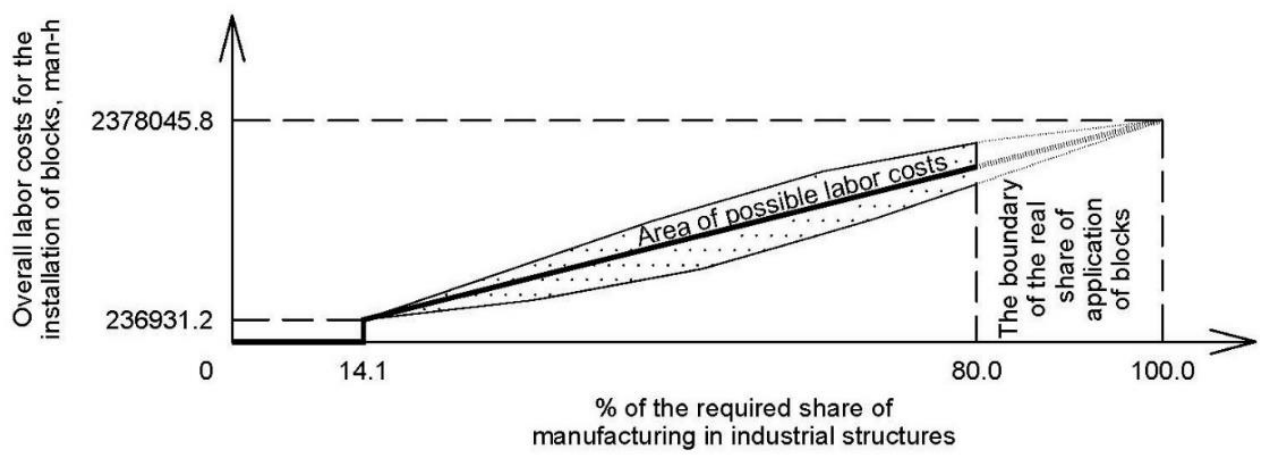

Fig. 1. The magnitude of labor costs for the installation of reinforcement blocks, depending on the proportion of the use of reinforcement blocks in the construction of the reactor building of nuclear power plants.

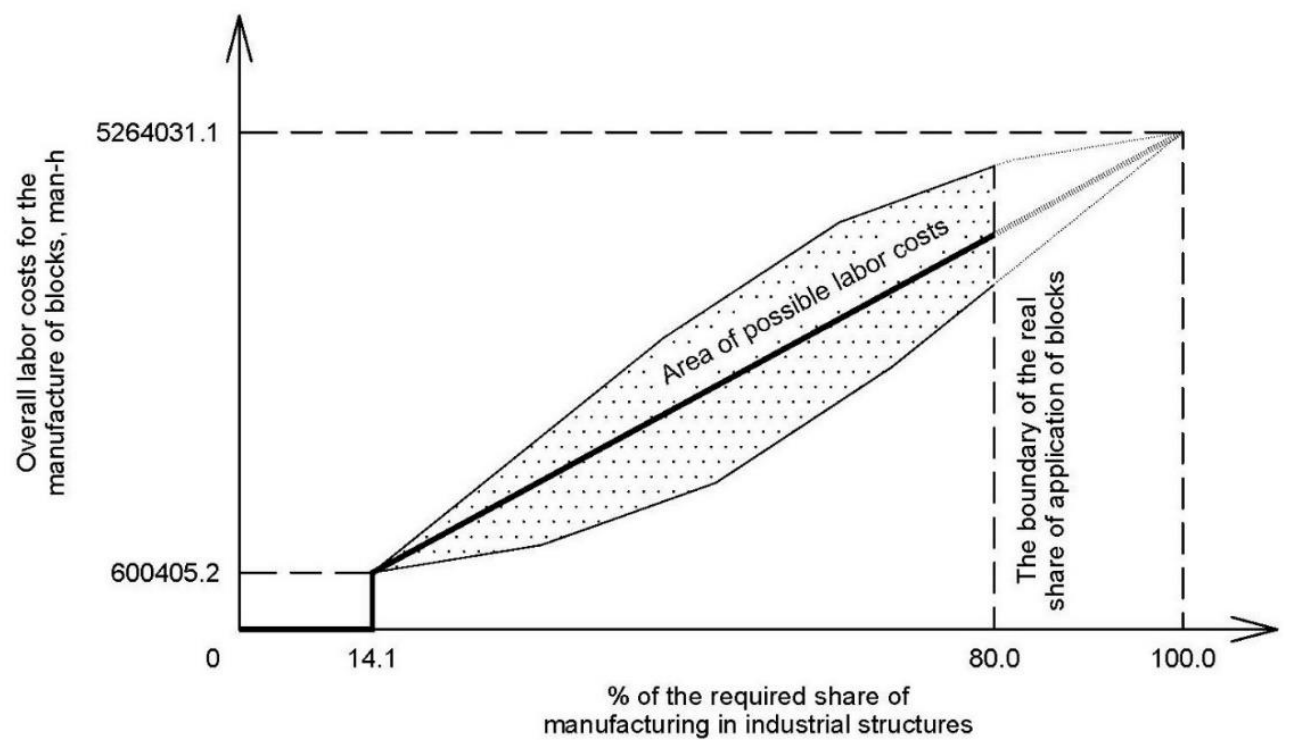

Fig. 2. The magnitude of labor costs for the industrial production of reinforcement blocks, depending on the proportion of the use of reinforcement blocks in the construction of the reactor building of nuclear power plants. 


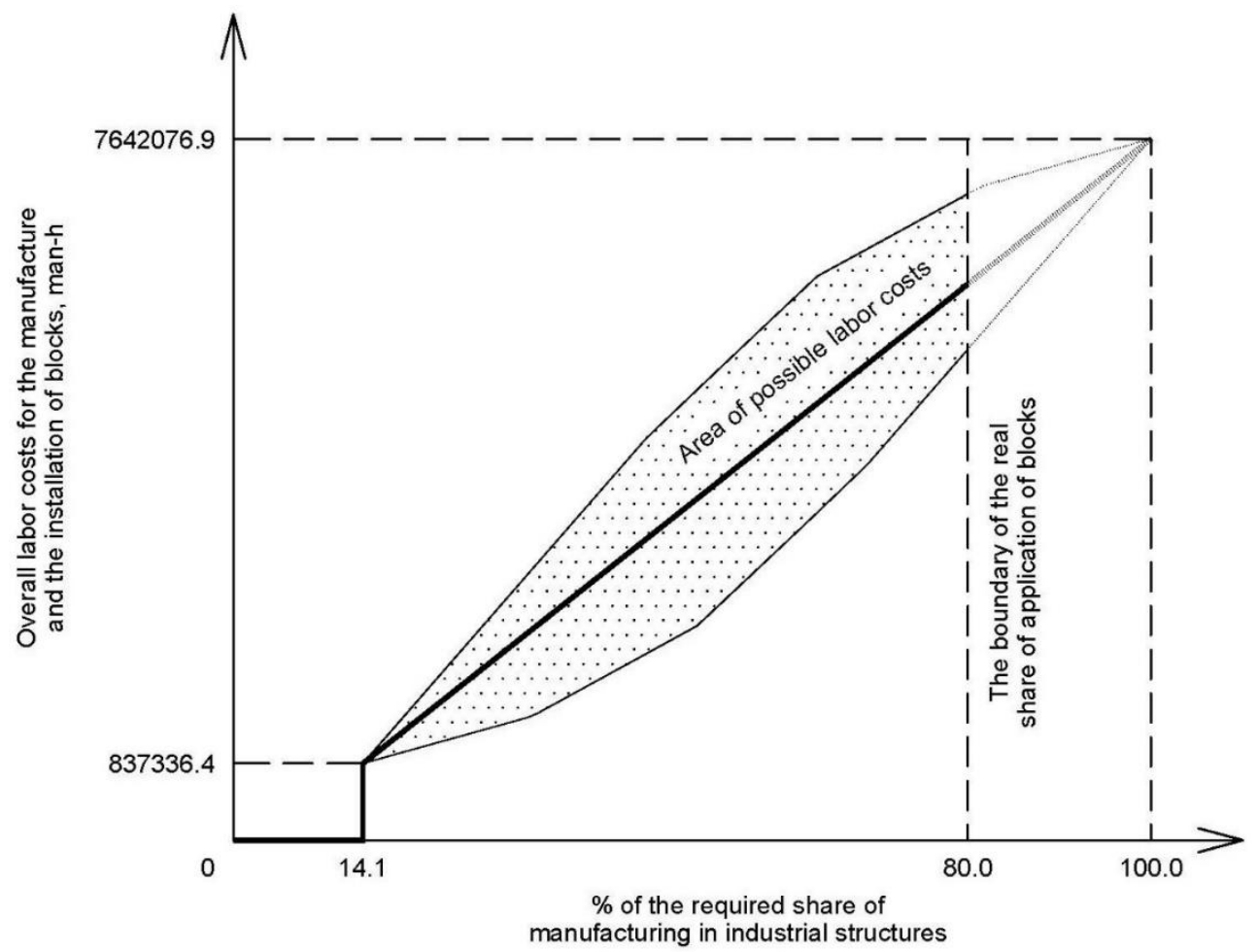

Fig. 3. The magnitude of overall labor costs for the industrial production and the installation of reinforcement blocks, depending on the proportion of the use of reinforcement blocks in the construction of the reactor building of nuclear power plants.

Earlier, a graph of the amount of labor costs for the industrial production of reinforced concrete blocks was obtained, depending on the share of using reinforced blocks during the construction of the nuclear power plant reactor building [9]. The graph is shown in Figure 2.

Summarizing these two graphs, we obtain the overall amount of labor costs for industrial production and installation, depending on the share of the use of reinforced blocks in the construction of the nuclear power plant reactor building. The graph is shown in Figure 3. The analytical form of the median of this dependence will look as follows:

$\mathrm{C}_{\text {over }}=79217.003 \cdot x-279623.4$

$\mathrm{C}_{\text {over }}$ - overall labor intensity of industrial production and installation of reinforced blocks for the reactor building of the NPP, man-h;

$x$ - the required share of manufacturing reinforced concrete structures of a reactor building in industrial structures, $\%$.

The demand for crawler and tower cranes, onboard vehicles and trailers will be considered as parameters of specific resource intensity. All specific needs will be determined for 1 man-hour of labor intensity of installation of structures. The formula for determining the specific resource intensity for each parameter will be written in the following form:

$$
r_{i}=\frac{Q_{i}}{n_{\text {worker }} \cdot t_{\text {shift }} n_{\text {shift }}}
$$

$r_{i}$ - specific resource intensity of the i-th parameter;

$Q_{i}$ - quantitative measure of the i-th parameter;

$n_{\text {worker }}$ - the number of workers in a brigade in 1 shift, man; 
$t_{\text {shift }}-$ shift duration (working time), h;

$n_{\text {shift }}$ - the number of shifts per day, day ${ }^{-1}$

We obtain that per $1(\operatorname{man}-\mathrm{h}) / \mathrm{m}^{3}$ labor intensity of installation of inner containment blocks per day 0.002 (man-h-day $)^{-1}$ crawler cranes with a lifting capacity of $1350 \mathrm{t}$,

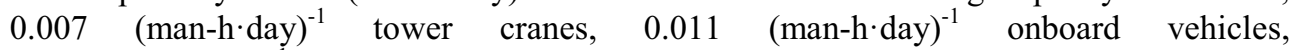
$0.002\left(\right.$ man-h·day) ${ }^{-1}$ trailers.

Since it is not possible to determine a quantitative change in the use of resources during the installation of blocks of various configurations, we will conventionally accept the obtained values constant for blocks of various configurations. Refinement of the obtained data is possible only on the basis of further collection of statistical information.

\section{Discussion}

The data obtained in this article make a great contribution to the issue of building an integrated model of an investment and construction project for the construction of a nuclear power plant. Based on the model, it is possible to more accurately analyze the reduction in the construction time of nuclear power plants. Also, the model should help in determining the optimal distribution of labor costs between the participants in the investment and construction project. This model should become the basis for a new methodology for forming the organizational structure of the project for large-block construction of a nuclear power plant. To build a model, it is necessary to additionally analyze other components of the NPP construction project.

Also, the obtained data can be used to clarify existing standards. The data obtained is based on actual labor costs in a real construction project. They take into account the use of modern technologies and various other nuances.

\section{Conclusions}

1. Large-block construction is a relevant and promising method for organizing the construction of new NPP power units, including in the implementation of foreign projects. Having massive experience in the construction of about $14 \%$ of reinforced concrete structures in reinforced formwork blocks, it is possible to bring this figure to $80 \%$.

2. The dependence of the amount of labor costs for the installation of reinforced blocks, depending on the share of using reinforced blocks during the construction of the reactor building of a nuclear power plant, allows you to determine the need for labor costs with partial or maximum possible use of industrial structures.

3. Based on the dependence of the value of the total labor costs for the industrial production and installation of reinforced blocks, depending on the share of using reinforced blocks during the construction of the nuclear power plant reactor building, it will make it possible to clarify the calculation model for managing labor costs and organize a nuclear power plant construction project.

4. Based on the data obtained, it can be seen that directly on the construction site, on average, only $28-31 \%$ of labor costs are required. The rest of the labor costs are transferred to the construction and installation base or other industrial enterprises. This requires a radical transformation of the organizational structure of the investment and construction project.

5. By reducing labor costs at the construction site, it is possible to reduce the overall construction time of the reactor building. This will allow achieving economic benefits due to the early commissioning of the power unit. However, additional costs are required to organize the production of reinforced blocks. Thus, a high percentage of construction of 
buildings and structures of nuclear power plants is relevant for plants with a large number of power units.

\section{References}

1. A.A. Morozenko, A.A. Shashkov, Organizational and technological aspects of largescale construction of nuclear power plants, Science and Business: Development Ways, 5(95), pp 28-33 (2019)

2. A. Osokin A, VVER-TOI Construction Organization Project, Rosenergoatom, 12 (2012)

3. A.A. Morozenko, I.E. Voronkov, Improving the efficiency of organizational and technological solutions when constructing nuclear power plants on the basis of contemporary russian and foreign experience, Promyshlennoe I grazhdanskoe stroitel'stvo, 10, pp 74-79 (2014)

4. V.A. Dorf, R.O. Krasnovskiy, I.S. Krol, D.E. Kapustin, Prefabricated-cast-in-place technology of building contruction using nondetachable steel-fibre-concrete form, North of Russia: Strategies and Development Prospects (Mat. of the II All-Russian Scien. and Pract. Conf.), pp 77-82 (2016)

5. D.E. Kapustin, K.V. Rogachev, A.E. Kapustin, Application of permanent fiber reinforced concrete formwork, Regional architecture and engineering, 2, pp 102-109 (2014)

6. B.K. Pergamenshchik, V.A. Undozjorov, A model of the labor productivity dependence on workforce density, E3S Web of Conf. 22nd Int. Scien. Conf. on Construction the Formation of Living Environment, FORM 2019 C. 06020 (2019)

7. A.A. Morozenko, V.V. Belov, I.E. Voronkov, A.S. Kabanov, Research of functional and technological limitations in large-block construction of nuclear power plants, Actual problems of the construction industry and education (col. of rep. of the First National Conf. (Moscow, Sep. 30, 2020)), Moscow: MISI - MGSU Publishing House, pp. 341-348 (2020)

8. A.A. Kholopov, K.A. Dudkevich, B.K. Pergamenshchik, Transportation and installation of enlarged NPP elements, Vestnik MGSU, 4, pp 266-274 (2010)

9. A.A. Morozenko, A.A. Shashkov, Resource assessment of large-block construction of NPP, IOP Conf. Ser.: Mater. Sci. Eng. 869062025 (2020)

10. A.A. Morozenko, Material and resource assessment of sustainable functioning of enterprises in the construction industry, Vestnik MGSU, 2, pp 261-263 (2010) 